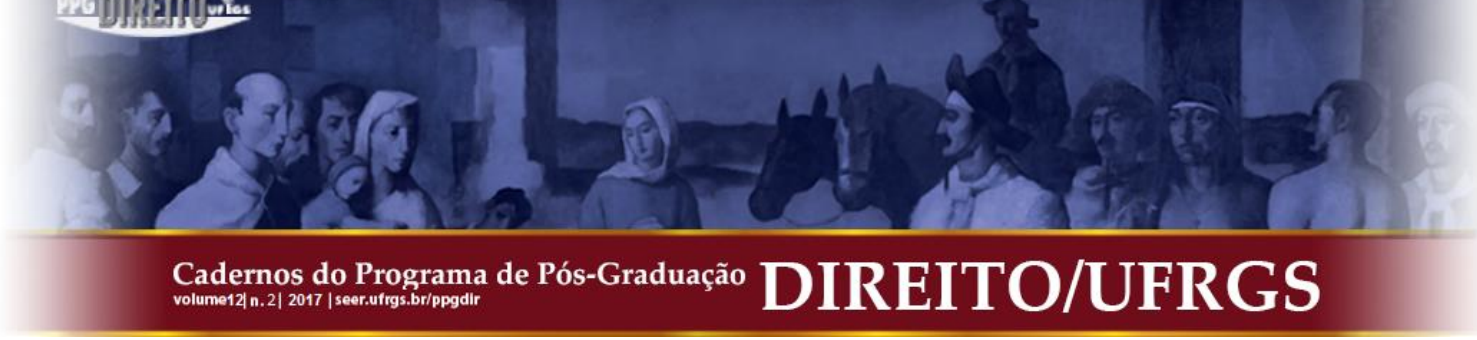

\title{
TRANSFERÊNCIA DE TECNOLOGIA EM CONTRATOS INTERNACIONAIS DE FORNECIMENTO - DESENVOLVENDO A INDÚSTRIA LOCAL
}

\author{
TECHNOLOGY TRANSFER IN SUPPLY INTERNATIONAL AGREEMENTS -
}

DEVELOPING THE LOCAL INDUSTRY

\section{Caetano Dias Corrêa*}

Patrícia Loureiro Abreu Alves Barbora**

\begin{abstract}
RESUMO: A transferência de tecnologia é necessária para a execução de contratos de fornecimento de equipamentos, por meio de patentes ou know-how, tendo em vista sua necessidade para a operação e manutenção regular do equipamento por parte do contratante, inclusive para além do prazo de garantia. Não obstante, os termos e condições da transferência de tecnologia não são adequadamente estabelecidos nos contratos celebrados pelos contratados. A fim de evitar futuras controvérsias sobre essa questão, é obrigatória a disposição pontual dos artigos relacionados à transferência de tecnologia no contrato celebrado pelas partes. A previsão dos termos apropriados de transferência de tecnologia em contratos internacionais é útil para melhorar a indústria local e o desenvolvimento do país. Nesse sentido, o presente trabalho visa a pontuar, a partir do método dedutivo, de que forma e são fixadas as condições referentes à transferência de tecnologia em contratos internacionais de fornecimento de equipamentos celebrados no Brasil, bem como as possibilidades de compreensão de tal dinâmica como instrumento de desenvolvimento, a partir da transmissão de conhecimento oriundo de países desenvolvidos aos países em desenvolvimento. Para tanto, em sua primeira seção, busca perceber a correta compreensão do atual panorama de conformação da sociedade - a sociedade da informação - em suas origens, características e dinâmicas, assim como do próprio conceito de desenvolvimento. Em seguida, na segunda parte, relaciona referidos temas em uma análise que compreende sua complexidade, apresentando as formas de transferência de tecnologia usualmente contratadas em especifico, por meio de contratos de fornecimento de equipamentos de engenharia.
\end{abstract}

PALAVRAS-CHAVE: Transferência de Tecnologia. Desenvolvimento. Contratos Internacionais.
ABSTRACT: Technology transfer is necessary for the accomplishment of equipment supply agreement, either using patents or know how process. This operation serves to the regular equipment operation and maintenance by contractor also to permit the regular execution of the equipment further the guarantee term. Notwithstanding, the terms and conditions of technology transfer are not properly settle in the agreements executed by contractors. In order to avoid future controversies about this question is mandatory the punctual disposition of the articles related to technology transfer in the agreement executed by the parties. The appropriated terms of transfer of technology in international contracts is helpful to improve the local industry and the development of the country. In this sense, the present work aims to present, from the deductive method, how the conditions related to the transfer of technology in international contracts of equipment supply in Brazil are set, as well as the possibilities of understanding such dynamics as instrument of development, from the transmission of knowledge from developed countries to developing countries. For this purpose, in its first section, it seeks to verify the correct understanding of the current panorama of the formation of society the information society - in its origins, characteristics and dynamics, as well as the concept of development itself. Then, in the second part, it relates these themes in an analysis that understands its complexity, presenting the forms of transfer of technology usually contracted in specific, through contracts of supply of engineering equipment.

KEYWORDS: Technology Transfer. Development. International Contracts.

SUMÁRIO: Introdução. 1 Tecnologia, Desenvolvimento e Sociedade da Informação. 1.1 Aspectos Conceituais da Sociedade da Informação. 1.2 A Tecnologia como Base e como Destino da Sociedade da Informação. 1.3 Transferência de tecnologia e desenvolvimento. 2 Contratos de Transferência de Tecnologia. 2.1 Aspectos Conceituais. 2.2 Formas de Transferência de Tecnologia. 2.3 Transferência de Tecnologia por meio de Contratos de Fornecimento de Equipamentos. Conclusão. Referências.

* Doutor e Mestre em Direito pela Universidade Federal de Santa Catarina (UFSC). Professor do Curso de Graduação em Direito da Universidade Federal de Santa Catarina (UFSC). Professor do Curso de Graduação e Especialização em Direito do Centro Universitário Católico de Santa Catarina.

** Doutora e Mestre em Direito pela Universidade Federal de Santa Catarina (UFSC). Professora Visitante de Direito Administrativo no Curso de Graduação em Administração de Empresas no Centro de Ciências da Administração e Socioeconômicas da Universidade do Estado de Santa Catarina (UDESC). 


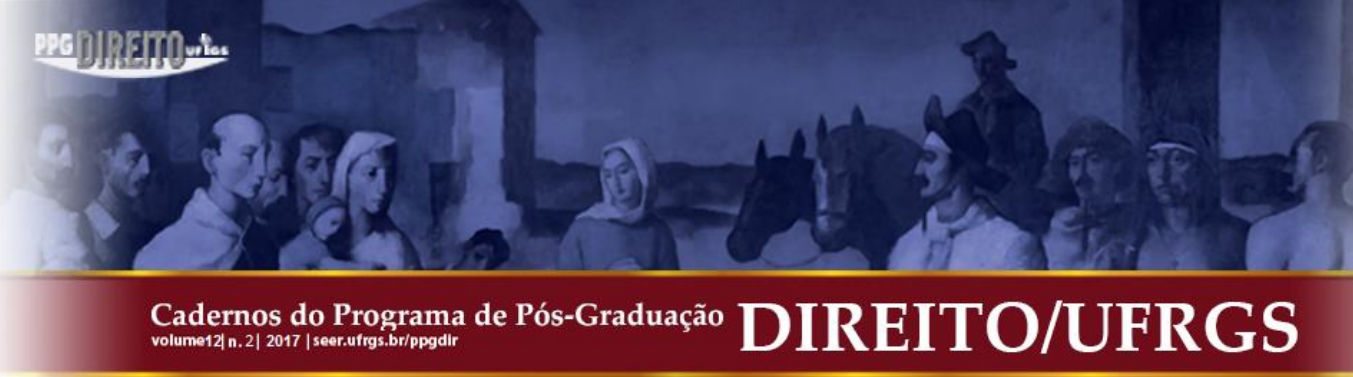

INTRODUÇÃO

O presente trabalho visa a pontuar, de maneira sucinta, a partir do método dedutivo, de que forma e com base em quais critérios jurídicos são fixados os termos, condições e cláusulas referentes à transferência de tecnologia em contratos internacionais de fornecimento de equipamentos celebrados no Brasil, bem como as possibilidades de compreensão de tal dinâmica como instrumento de desenvolvimento, a partir da transmissão de processos, informação e conhecimentos oriundos de países desenvolvidos (geralmente detentores da tecnologia) aos países em desenvolvimento.

Todavia, a correta compreensão do panorama demanda uma revisão teórica acerca do atual modelo de conformação da sociedade - a sociedade da informação - em suas origens, principais características e dinâmicas, assim como do próprio conceito de desenvolvimento, a fim de que se possa, posteriormente, relacionar referidos temas em uma análise que compreenda sua inter-relação e complexidade.

Assim, o primeiro tópico se ocupará em apresentar os aspectos conceituais necessários ao entendimento do tema proposto. O segundo, por sua vez, se debruçará especificamente sobre os contratos em tela, de modo a verificar as possibilidades de pactuação da transferência de tecnologia e suas principais consequências.

A segunda parte deste artigo, por sua vez, apresentará as formas de transferência de tecnologia usualmente contratadas em especifico, de forma consequente, por meio de contratos de fornecimento de equipamentos de engenharia.

\section{TECNOLOGIA, DESENVOLVIMENTO E SOCIEDADE DA INFORMAÇÃO}

\subsection{Aspectos Conceituais da Sociedade da Informação}

A compreensão do tema proposto no presente texto não dispensa a observação, por mais clichê que ela possa parecer, dos processos que culminaram em uma nova conformação da sociedade e das formas de organização social, reunidos no conceito de sociedade da informação.

Primeiramente, deve-se remontar ao que se convencionou denominar de fenômeno (ou processo) de globalização, ante sua indelével característica de aproximação espacial e de compressão temporal, numa referência ao modo como a comunicação eletrônica instantânea vem desgastando as limitações da distância e do tempo na organização e na interação sociais 


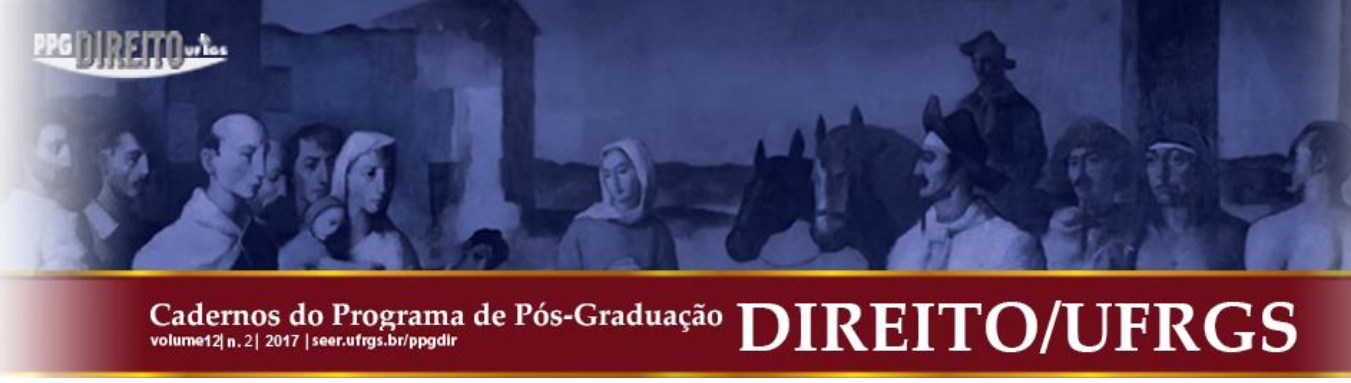

(HELD; MCGREW, 2001, p.11).

O desenvolvimento das tecnologias da informação e do conhecimento (telecomunicações, computador, internet etc.) ocasionou um incremento da interligação entre as diversas localidades, bem como a reflexividade de tais fluxos de comunicação, trazendo à tona uma série de novas realidades em escala global (GIDDENS; 2000, p. 20). As implicações dessa nova realidade se fazem sentir tanto no mercado e no mundo dos negócios, quanto nos aspectos mais cotidianos da existência (BAUMANN; 1999, p.7).

Os habitantes do planeta, assim, passaram a interagir em níveis crescentes. As trocas culturais adquiriram uma dimensão nunca antes vista e se passaram a se desenrolar com rapidez e abrangência. Igualmente, os mercados, dada a mobilidade inerente ao capital, assinalaram uma presença significativa por todo o mundo, transnacionalizando as cadeias produtivas e as relações de consumo, bem como possibilitando a realização instantânea de investimentos em fundos e bolsas de todos os países neles inseridos (CORRÊA; 2004, p. 233).

A sociedade da informação se insere precisamente nesse contexto do fenômeno da globalização, uma vez que sua existência e consolidação enquanto modelo social decorre de relações e estruturas desenvolvidas no âmbito das transformações civilizacionais experimentadas nos últimos anos. Igualmente, a sociedade da informação pode ser caracterizada a partir desse panorama, revelando, como decorrência desse mesmo incremento tecnológico, a conformação diversas vias interligadas de comunicação digital e o amplo recurso a meios informáticos, ocasionando, por conseguinte, uma ênfase na valorização do conhecimento, da pesquisa e da informação (WACHOWICZ; 2006, p. 72).

Dessa forma, as noções de acesso e de rede ganham especial relevo, figurando agora como conceitos operacionais que revelam não só possibilidades de compreensão da dinâmica dos meios de comunicação, mas sim como elementos fundamentais para a consolidação de um novo modelo organizacional da sociedade, em superação ao modelo de sociedade industrial.

Se antes o ambiente da fábrica e os modelos de gerenciamento da produção industrial verberavam na própria organização das instâncias de relações sociais e trocas interpessoais, atualmente são os fluxos de informação disponibilizados em rede, bem como as possibilidades de acesso a tais fluxos, que dão o tom da organização da sociedade e de suas dinâmicas sociais. Com efeito, da mesma forma que a energia elétrica viabilizou a indústria como modelo socioeconômico, a internet passou a ser a base tecnológica para a forma organizacional da era da informação: a rede (CASTELLS; 2003, p. 7).

Cadernos do Programa de Pós-Graduação em Direito PPGDir./UFRGS | Edição Digital | Porto Alegre | Volume XII | Número 2 | 2017 | P. 138 - 155 


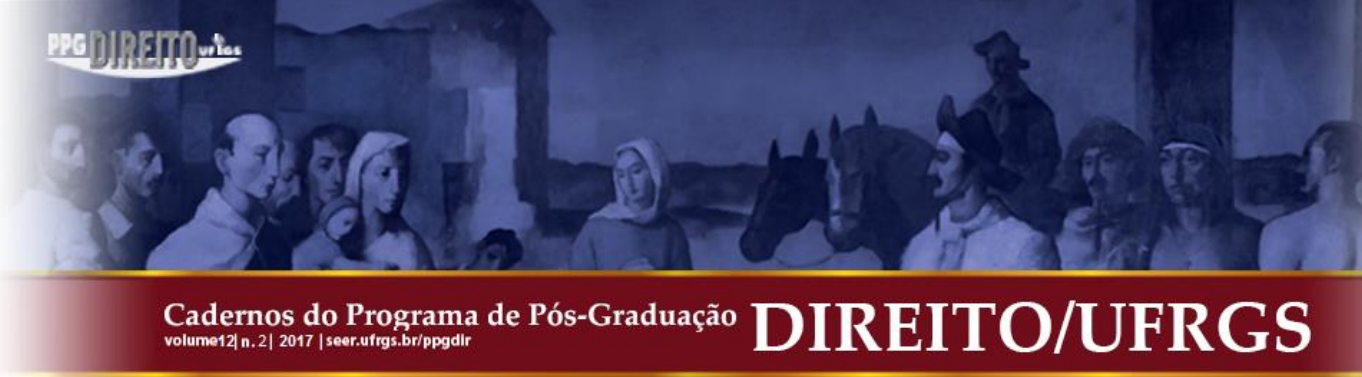

Para CASTELLS (2003, p. 7), a rede possui muitas vantagens como ferramenta de organização em virtude de sua inerente flexibilidade e adaptabilidade, em oposição a estruturas centralizadas e verticalizadas. Porém apresenta dificuldades em coordenar funções e concentrar recursos em metas específicas. Todavia, em virtude das novas tecnologias de comunicação e de informação, tem sido possível à rede, enquanto modelo de organização, manter suas qualidades e agregar em si tarefas de coordenação e administração. Tem sido possível congregar a estrutura descentralizada de execução de tarefas com decisões coordenadas, a expressão individualizada e a comunicação global.

\subsection{A Tecnologia como Base e como Destino da Sociedade da Informação}

A contextualização realizada no item anterior permite que se perceba prontamente o lugar de destaque assumido pela tecnologia (sobretudo pela tecnologia da informação e do conhecimento) em todo esse novo cenário. Tanto a ideia de fenômeno da globalização quanto a noção de sociedade da informação comportam em seu âmago o desenvolvimento tecnológico, sempre concebido como instrumental basilar a todas as transformações simbolizadas por aqueles dois conceitos.

Ademais, também é necessário frisar que

a tecnologia ocupa papel de inegável proeminência no contexto sócio-econômico. No
plano empresarial, é ela fator que garante a conquista de novos mercados, bem como
a manutenção do agente econômico em um contexto cada vez mais competitivo. Pelo
prisma do Estado e da sociedade, observa-se que a detenção da tecnologia é critério
fundamental para uma adequada inserção no cenário internacional, e também que
essa, quando adequadamente utilizada contribui sobremaneira para o bem-estar de
seus cidadãos. (KEMMELMEIER; SAKAMOTO, 2006, p. 129)

Há, portanto, uma dupla dimensão da tecnologia a ser compreendida: como ferramental necessário às transformações que originaram o novo modelo social; e como ativo, vetor de desenvolvimento econômico e social. Ou seja: no panorama da sociedade da informação, a tecnologia (ou ainda as tecnologias) da informação e do conhecimento, além de ter propiciado a amplificação do fenômeno da globalização e a transposição da sociedade industrial, apresentase como um dos principais instrumentos de geração de riqueza e de desenvolvimento.

Todavia, sempre que se adentra nessa segunda dimensão de abordagem da tecnologia, isto é, sempre que se analisam as perspectivas de desenvolvimento a partir da tecnologia, uma

Cadernos do Programa de Pós-Graduação em Direito PPGDir./UFRGS | Edição Digital | Porto Alegre | Volume XII | Número 2 | 2017 | P. 138 - 155 


\subsection{Transferência de Tecnologia e Desenvolvimento}

É necessário, quando se fala em tecnologia e, consequentemente, em transferência de tecnologia, que se tenha em conta uma compreensão de sua importância para o desenvolvimento. Porém, antes de tudo, é necessário compreender o que pode ser entendido como desenvolvimento, a fim de que se possa perceber e analisar os impactos e contributos da transferência de tecnologia na conformação de sociedades desenvolvidas.

Dentre as várias vertentes teóricas a se debruçar sobre a matéria e diversos significados empregados ao conceito em questão, o presente texto abordará o desenvolvimento como sendo um processo de expansão das liberdades reais que as pessoas podem desfrutar (SEN, 2010, p. $52)$.

Quer-se estabelecer uma concepção de desenvolvimento para além de um enfoque reducionista, o qual busca identificar desenvolvimento com meros crescimento econômico, aumento de renda, avanço tecnológico ou modernização, quando, na verdade, todos esses elementos devem servir como meio de expandir as liberdades humanas, as quais não dependem somente da conjuntura econômica, mas também de outros fatores, tais como culturais, sociais, políticos, bem como dos direitos civis etc. (SEN, 2010, p. 32).

Assim, enquanto meio (e não fim), as oportunidades de acesso e participação no comércio e na produção, isto é, nos mercados, podem auxiliar, potencializar, a geração de riqueza individual, além de recursos públicos para os serviços sociais (SEN, 2010, p. 25). Não se pode, contudo, incorrer no equívoco de identificar o crescimento econômico com o conceito de desenvolvimento. A ideia de crescimento econômico é mais restrita, ligada diretamente ao incremento financeiro daqueles que possuem as condições matérias de gerar riqueza, como bem explicam BARRAL e PIMENTEL (2006, p. 27):

O crescimento econômico, que é quantitativo, por suposto não é sinônimo de desenvolvimento. As mega-empresas, que patrocinam pesquisas, que combinam recursos públicos e privados, são também as que mantém a posse e a propriedade da tecnologia de ponta. Calculam todos os detalhes dos seus custos e lucros, pressionando os governos a exigir mais proteção e assegurar o reembolso do investimento com dividendos substanciais.

O conceito de desenvolvimento é, pois, notadamente mais amplo e deve estar atrelado à ideia de liberdade. 


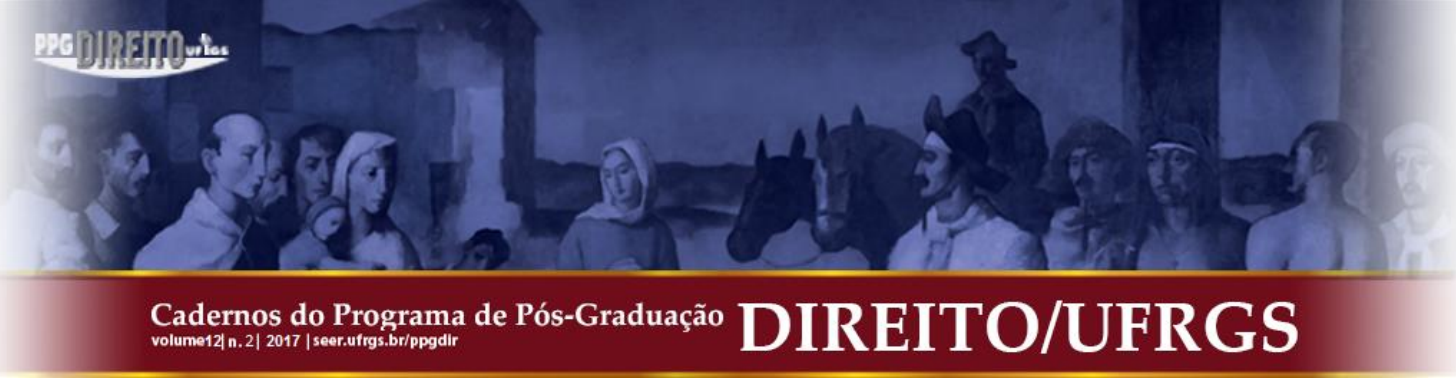

Por sua vez, a transferência de tecnologia pode assumir a posição de importante instrumento de desenvolvimento, na medida em que, quando efetivada de maneira a não tornar o receptor um mero dependente do conhecimento produzido pelo transmissor, poderá prover liberdade e autonomia de produção.

Todavia, cumpre aqui realizar uma importante distinção. Deve-se ter em conta que

o desenvolvimento tecnológico está diretamente relacionado ao desenvolvimento social. Porém, a relação de domínio e dependência tecnológica gera um círculo vicioso, principalmente quando essa transferência de tecnologia não vem acompanhada de investimento em pesquisa, principalmente universitária, e está destituída de caráter de colaboração, para que no futuro essa relação de dependência dê lugar a uma relação de cooperação científica ou tecnológica. (ROCHA, 2006, p. 154).

Ou seja: a transferência de tecnologia deve ser buscada não para manter a submissão (garantida, no caso, pelos instrumentos jurídicos de proteção da propriedade intelectual) mas antes para estimular a colaboração. Caso contrário, não se poderá falar de sua utilização como vetor de desenvolvimento, uma vez que ancorada claramente em uma prática oposta à ampliação da liberdade.

Apresentando um panorama um tanto quanto pessimista, fulcrado justamente nessa noção de dependência, MELLO (1993, p. 181) entende que um dos grandes problemas do Direito Internacional Econômico e da nova ordem econômica internacional é a transferência de tecnologia, que os países ricos só transferem aos pobres quando ela se encontra ultrapassada. Para o autor, a transferência de tecnologia realizada na sociedade internacional não atende aos países pobres e sofre uma série de críticas, pois, na maioria das vezes, não beneficia toda a sociedade do Estado, mas é feita apenas em proveito de uma filial ou subsidiária de uma empresa cuja matriz está no exterior. Da mesma forma, a transferência é quase sempre de técnicas consideradas obsoletas, pois a tecnologia transferida nem sempre é a que atende às necessidades do desenvolvimento, além de o preço da transferência ser muito elevado para os países pobres. Conclui, então, que o processo de transferência de tecnologia acaba por aumentar a dependência dos países pobres.

Nada obstante, constata-se que,

apesar de a transferência tecnológica dos países desenvolvidos para aqueles em desenvolvimento ter representado uma importante e necessária contribuição para que os países periféricos alcançassem um certo grau de desenvolvimento econômico, este mesmo mecanismo de inovação tem tornado estes países tecnologicamente dependentes dos países centrais, uma dependência que gravemente afeta seu 


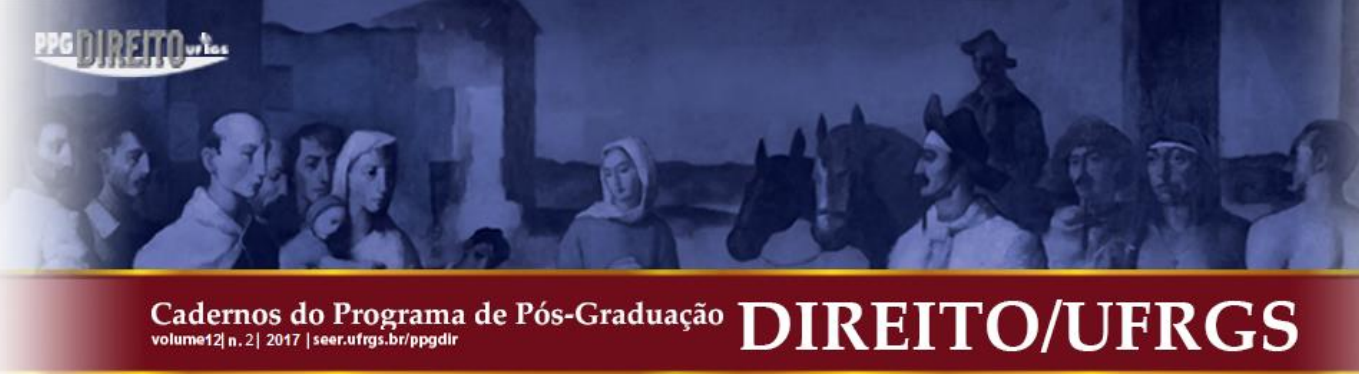

desenvolvimento social e que, além disto, tem se tornado difícil de ser superada. (CYSNE, 1996, p. 8).

Pode-se compreender, portanto, que a transferência de tecnologia, para que possa ser utilizada como um instrumento de desenvolvimento, pressupõe que a ideia de colaboração (com a possibilidade de realização de pesquisas que ampliem as possibilidades de utilização dos processos e conhecimentos transmitidos) venha a suplantar a noção pura e simples de proteção à propriedade intelectual. De fato, o aumento da proteção à tecnologia não significa que haja sua efetiva transferência, a qual somente será viabilizada de modo compatível ao desenvolvimento mediante a capacitação tecnológica dos centros de pesquisa local nos países em desenvolvimento (BARRAL; PIMENTEL, 2006, p.12), de modo que estes venham não só mais a verberar o que é desenvolvido fora, mas possam digerir e incrementar os processos e conhecimentos transmitidos.

Nesse sentido,

é largamente aceito que existe uma relação forte entre a autonomia tecnológica e econômica de um país e sua capacidade para desenvolver pesquisas científicas e tecnológicas e criar condições para solucionar problemas técnicos, econômicos e sociais. Esta autonomia é fundamental para o desenvolvimento de todos os níveis da sociedade. O essencial é que o resultado de tais pesquisas possa ser fácil e rapidamente transferido e absorvido pelos setores econômicos e sociais. Para tanto, fundamental que um corpo estruturado de conhecimento possa dar ao país a capacidade necessária para produzir, transferir e/ou absorver novas tecnologias e/ou processos tecnológicos e, assim, gerar soluções para os seus problemas diários. (CYSNE: 1996, p. 7).

A transferência de tecnologia, sobretudo em contratos internacionais de fornecimento de equipamentos, deve estar atrelada, portanto, a esse panorama de desenvolvimento enquanto ampliação da liberdade.

O próximo tópico analisará especificamente as maneiras de estipulação apropriada de termos e cláusulas de transferência de tecnologia em tais contratos, bem como seu proveito como potencializados da indústria local e, por conseguinte, do desenvolvimento do país. 


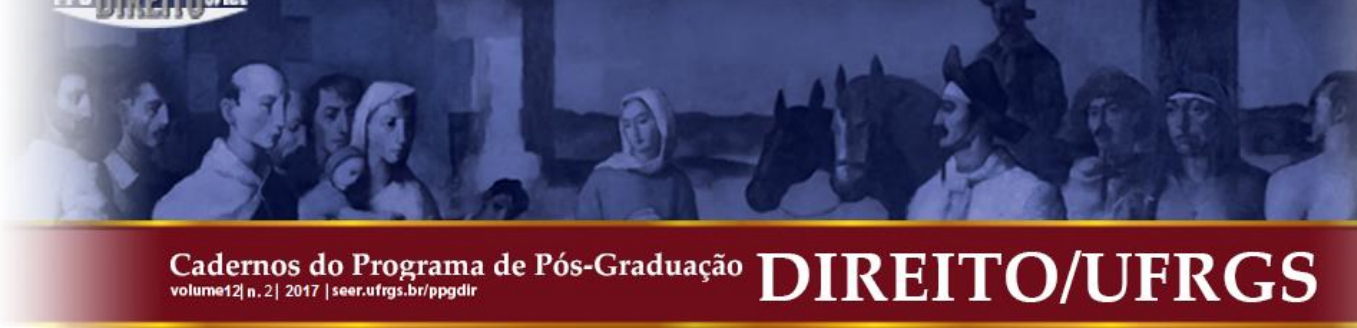

\section{CONTRATOS DE TRANSFERÊNCIA DE TECNOLOGIA}

\subsection{Aspectos Conceituais}

Considera-se tecnologia todo o conhecimento e informação capaz de agregar vantagem competitiva no setor comercial ou industrial. Neste sentido, conhecimento é entendido como o saber tecnológico e científico, seja no domínio teórico ou prático, enquanto que informação é o conjunto de esclarecimentos que permite a utilização do conhecimento. (FLORES, 2008, p. 45)

Além disso, verifica-se a importância da tecnologia não apenas como um bem imaterial, negociável e capaz de servir como mote ao desenvolvimento industrial, mas também a aplicação desta em outros projetos. Neste sentido, necessário acrescentar que "se trata de conhecimento teórico ou prático, que, por si só, ou com o auxilio de equipamento adequado, permita a realização de instalações ou serviços condizentes à obtenção de um produto, projeto e/ou a construção de um equipamento.” (ZABALO VIDAURRAZAGA, 1975, p. 235)

Assim sendo, a tecnologia representa um ativo de grande importância para os setores econômicos, tanto aqueles envolvidos na pesquisa e desenvolvimento de novas tecnologias, ou no seu aprimoramento, quanto para os envolvidos com a aplicação da tecnologia em bens e serviços.

Já a propriedade intelectual pode ser definida como uma categoria de direitos intangíveis que protegem produtos comercialmente valiosos do intelecto humano. De acordo com GARNER (2009, p. 27), “a categoria compreende principalmente direitos de marcas, direitos autorais e patentes, mas também inclui direitos de segredos comerciais, direitos de publicidade, direitos morais e direitos contra a concorrência desleal".

Sendo atribuído à propriedade intelectual o caráter de direito patrimonial, é possível que o titular, por meio de um negócio jurídico lícito, tendo sido ajustado o preço e condições negociais, transmita ou autorize a exploração por terceiros. (PIMENTEL; BARRAL, 2007, p. 16).

Destaca-se que a transmissão de tecnologia não significa a mudança do possuidor ou detentor da tecnologia, mas o repasse do conhecimento utilizado na ciência aplicada à técnica, seja industrial ou de serviços.

Estes instrumentos de transferência tanto podem regular o repasse de tecnologia patenteada como não patenteada, ou ainda mistos, relacionados à tecnologia sob patente em 


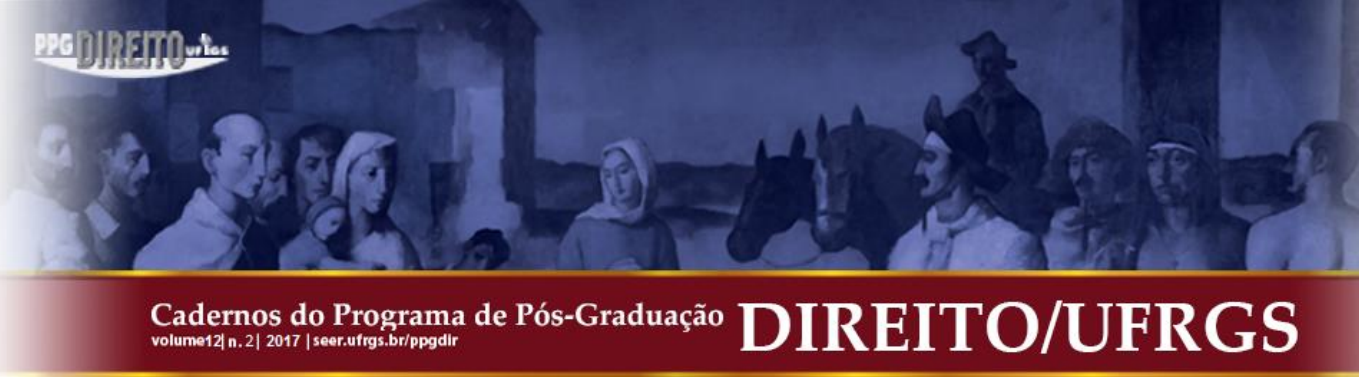

de forma independente ou em associações com uma patente tecnológica.

Em se tratando de contratos de transferência de tecnologia como instrumentos de desenvolvimento econômico, há necessidade de uma contrapartida para o capital empregado nos estudos e pesquisas investidas na nova tecnologia, o que é obtido, usualmente, por meio da celebração de um contrato de transferência de tecnologia, mediante remuneração. Como afirmam KEMMELMEIER e SAKAMOTO (2007, p. 136),

É usual que o detentor da tecnologia apresente interesse em permitir que outros se utilizem daquela pagando-lhe a respectiva contraprestação pecuniária, bem como há o interesse da outra parte em explorar essa tecnologia, evitando assim os custos da pesquisa e desenvolvimento, mas beneficiando-se com seus resultados.

Assim, a empresa responsável pela pesquisa, na qual foram investidos tempo e recursos financeiros pretende recuperar o investimento aplicado, inclusive para que o capital possa ser investido em outras pesquisas. Desta feita, os objetivos principais do desenvolver da tecnologia podem ser apresentados como sendo: (i) maximizar a remuneração, mediante a otimização de sua exploração; e (ii) utilizá-la como porta de entrada para novos mercados. (PRADO, 1997, p. 97).

No entanto, dentre os inconvenientes relacionados à transferência de tecnologia, incluem-se as pretensões egoístas dos transferentes, que longe de fomentar um verdadeiro e eficiente desenvolvimento, procuram apenas acentuar a dependência industrial entre os países, prejudicando o país receptor de tecnologia, pois uma política demasiadamente permissiva pode levar à submissão ou dependência à tecnologia estrangeira, bem como à impossibilidade de desenvolvimento de tecnologia própria (ASSAFIM, 2005, p. 359).

Ainda assim, de acordo com estatísticas do INPI os setores que mais transferem tecnologia, de acordo com o registro dos contratos correspondentes, são exatamente aqueles que têm maior volume de comércio. Ou seja, a transferência de tecnologia encontra-se diretamente relacionada ao aumento do comércio e, consequentemente, ao desenvolvimento econômico.

Neste sentido, confirma-se, como afirmado por ASSAFIM (2005, p. 359) que o progresso tecnológico é capaz de contribuir para aumentar o nível da qualidade de vida da humanidade, aumentando sua capacidade de consumo e tornando o trabalho mais digno. 


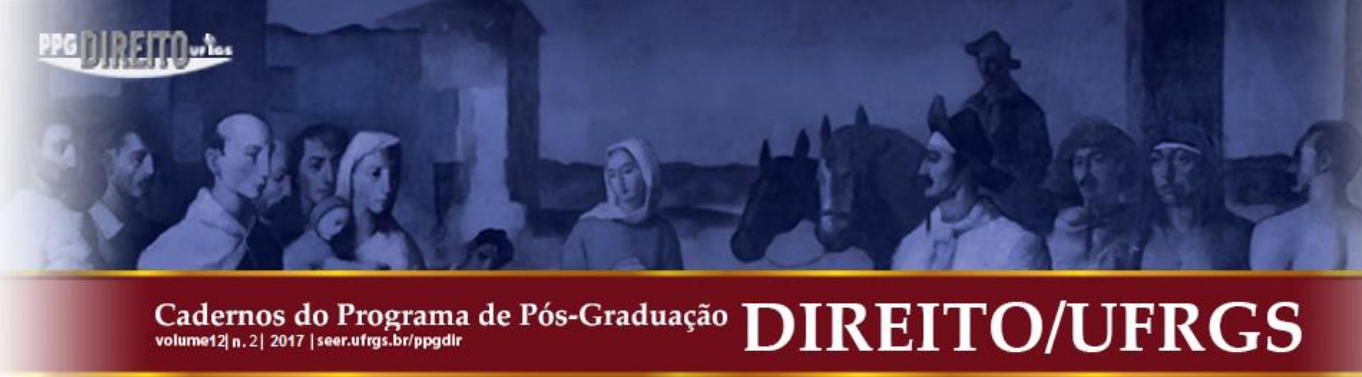

2.3 Transferência de Tecnologia por meio de Contratos de Fornecimento de Equipamentos

Grande parte da transferência de tecnologia é realizada por meio de contratos privados, os quais podem ser classificados em duas categorias: (i) aqueles que têm por objeto a transferência de tecnologia, tal como a transmissão de know how ou cessão de patentes; (ii) contratos que têm por consequência a transferência de tecnologia, tais como fornecimento de equipamentos, turn key.

Neste caso, a transmissão dos conhecimentos relacionados ao processo de desenvolvimento tecnológico é vinculada ao fornecimento de um bem ou prestação de um serviço. Assim sendo, o objeto contratual não é a transferência de tecnologia, mas esta se faz indispensável à consecução do contrato. Trata-se da negociação de tecnologia incorporada a um bem material, não em estado puramente intelectual.

Nesta hipótese, a tecnologia não é o objeto do contrato, que pode versar tanto sobre construção de complexos industriais (contratos de engenharia); distribuição de produtos; franquias, fornecimento de bens, assistência técnica, consultoria, investimento e outros, sendo a tecnologia necessária para a consecução do objeto contratual. A exploração da tecnologia, pelo cedente, se faz então de maneira indireta.

Neste sentido, afirma FLORES (2007, p. 92):

Muitos contratos realizam transferência de tecnologia de forma secundária, pois o objeto contratual é mais amplo e, na medida em que a negociação exige, a parte inclui a transferência de tecnologia como objeto acessório, parte do objeto principal. Esse é o caso dos contratos de franquia, de engenharia e projetos industriais, consórcios de patentes, distribuição e desenvolvimento tecnológico.

Assim, o valor relacionado à transferência de tecnologia é incorporado ao valor dos bens em negociação, sendo que tanto o valor da tecnologia quanto dos bens negociados seguem as regras do chamado bargain power respectivo do comprador e do vendedor (SANTOS, 1984, p. 125), o que por vezes dificulta ainda mais a transferência de tecnologia a países menos desenvolvidos, pois estes possuem menos capacidade de negociação (bargain power).

No entanto, por se tratar de bem acessório, os custos com pesquisa e desenvolvimento da tecnologia são diluídos para os diversos equipamentos negociados com vários receptores, fazendo com que a tecnologia cedida seja remunerada de forma adequada, além de agregar valor aos equipamentos negociados. 


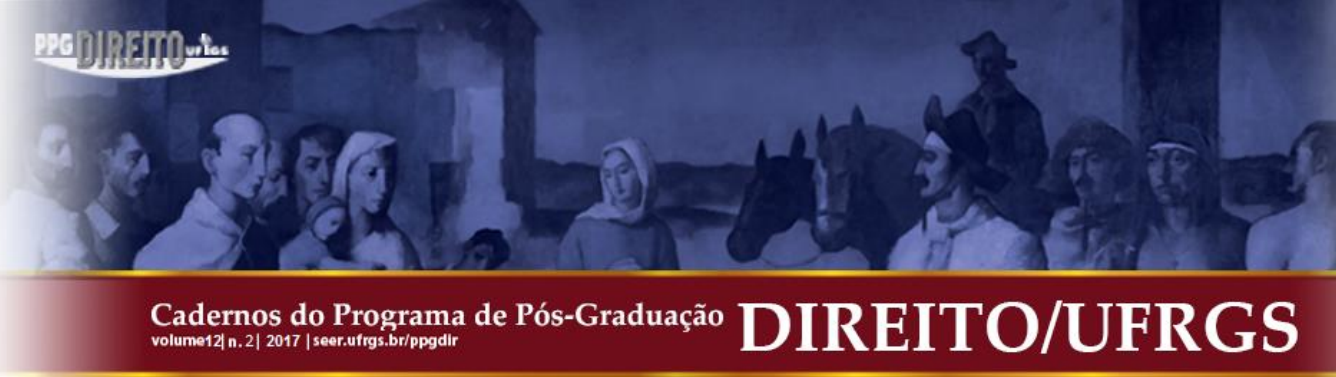

Ocorre que a transferência de tecnologia entre países desenvolvidos e menos desenvolvidos, apresenta riscos, como o pagamento de royalties excessivos, a aquisição de tecnologia obsoleta e inacabada, além da subordinação da economia do país receptor às grandes potências. (ASSAFIM, 2005, p. 369)

Por conta disto, o papel do Estado é de extrema importância, vez que a ação da iniciativa privada nem sempre é suficiente para regular essa questão. Assim, não só por meio de leis promulgadas pelo país, mas especialmente por meio das agências reguladores instituídas no Brasil, as quais condicionam a aprovação de novos projetos com a garantia de que nestes será utilizada tecnologia compatível àquela utilizada nos países cedentes de tecnologia. Tem-se como exemplo a proibição de instalação de equipamentos que contenham tecnologia obsoleta, obrigando que as empresas apenas importem equipamentos relacionados à energia, telefonia, dentre outros, que contenham tecnologia atual, e não obsoleta.

No entanto, é indispensável que, com estes equipamentos adquiridos, seja transferida também tecnologia, pois a capacitação tecnológica é fundamental para que o receptor possa gozar de autonomia, em relação ao transferente, quanto ao seu processo operacional, bem como à realização de adaptações e melhoramentos. (PRADO, 1997, p. 97)

Caso não ocorra, o receptor não só não terá plenas condições de gerir o bem adquirido, decorrente da falta de competência técnica, como estará permanentemente dependente do transferente, o que, para este, pode se mostrar uma excelente fonte de remuneração adicional, de forma permanente, pela prestação de serviços de assistência técnica.

Nesse exemplo, a transferência de tecnologia não é utilizada para desenvolvimento da indústria e, de forma geral, do país sede do receptor, mas apenas como uma forma de manutenção perpétua da dependência tecnologia verificada entre estes.

No que diz respeito aos contratos de fornecimento que incluem a entrega de bens, é a execução do contrato pela construção de qualquer edifício ou estrutura em qualquer terreno, na medida em que envolve o fornecimento de quaisquer bens através da sua incorporação no edifício, estrutura ou trabalhos. Neste caso, o fornecimento do equipamento não é suficiente para a execução do projeto e é necessária a integração dos equipamentos e do local em que serão instalados. Além disso, esses equipamentos precisam de procedimentos específicos para serem operados e mantidos.

Esses contratos de fornecimento de equipamentos têm como consequência a transferência de tecnologia e representam o produto da aplicação de uma tecnologia. No caso,

Cadernos do Programa de Pós-Graduação em Direito PPGDir./UFRGS | Edição Digital | Porto Alegre | Volume XII| Número 2 | 2017 | P. 138 - 155 


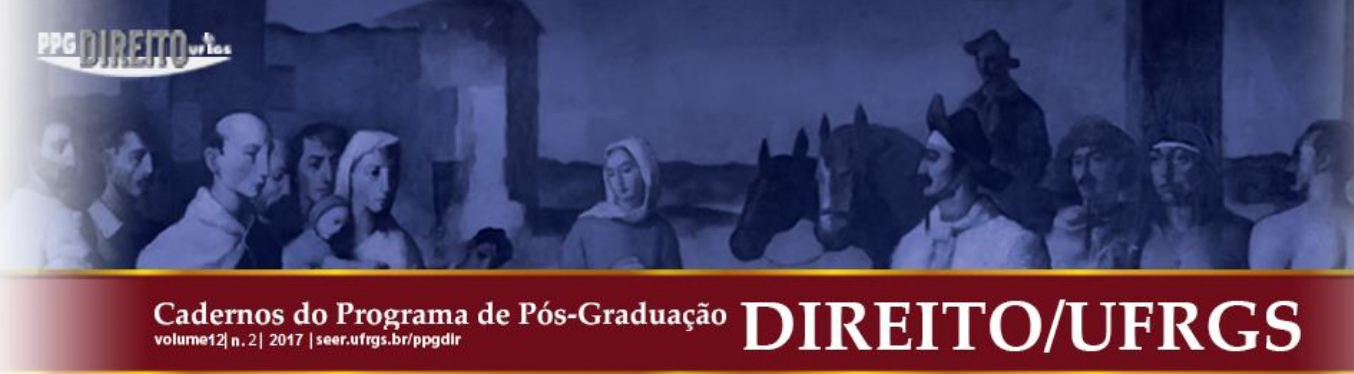

o projeto desenvolvido não é uma construção apenas, assim como não se pode falar que se trata apenas de uma tecnologia a ser incorporada pelo contratante, mas sim a todo o processo que alia experiência e utilização de bens.

Determinadas informações técnicas podem ser indispensáveis para a adequada exploração autorizada. Sua ausência pode representar um obstáculo para a assimilação de tecnologia e cumprimento dos objetivos de produção. A adequada exploração justifica a transferência de tecnologia.

Assim sendo, a expertise exigida para a implantação e operação dos equipamentos será fornecida por meio da prestação de serviços de consultoria e de assistência técnica, os quais exigem o conhecimento de técnicas e procedimentos específicos, relacionados à tecnologia empregada no desenvolvimento do equipamento, sendo estes conhecimentos detidos pela fornecedora.

Na situação exposta, está clara a necessidade de transferência de tecnologia quando da celebração de um contrato de fornecimento, a qual pode se dar mediante cláusulas específicas no contrato principal, ou por meio da celebração de um contrato acessório, relacionado especificamente à transferência de tecnologia.

A transferência de tecnologia por meio de tais contratos de fornecimento, ainda que acessória ou consequente, pode ser utilizada como uma importante ferramenta para o desenvolvimento econômico e social do país, desde que as partes negociem de forma justa, a permitir a capacitação tecnológica do receptor.

\section{CONCLUSÃO}

Diante do exposto, verifica-se que a transferência de tecnologia pode ser utilizada como ferramenta para o desenvolvimento dos países, em especial dos países em desenvolvimento, receptores de tecnologia dos países desenvolvidos.

Para que isto aconteça, no entanto, mister que a transferência de tecnologia seja acompanhada da capacitação tecnológica do receptor, de modo que este possa utilizá-la de forma construtiva e como alavanca ao desenvolvimento, não somente econômico, mas especialmente social da comunidade na qual a empresa receptora está inserida.

Para tanto, o cedente de tecnologia deve estar disposto a transferir tecnologia e treinar o receptor, para que este usufrua completamente do bem negociado. Ainda que o cedente de

Cadernos do Programa de Pós-Graduação em Direito PPGDir./UFRGS | Edição Digital | Porto Alegre | Volume XII | Número 2 | 2017 | P. 138 - 155 


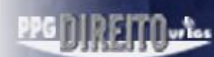

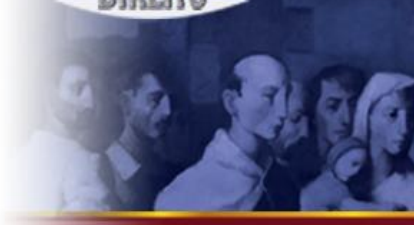 \\ Cadernos do Programa de Pós-Graduação volume12| n. 2 | 2017 | seer.ufrgs.br/ppgdir \\ DIREITO/UFRGS}

GIDDENS, Anthony. O mundo em descontrole. Rio de Janeiro: Record, 2000.

HELD, David. McGREW. Anthony. Prós e contras da globalização. Tradução de Vera Ribeiro. Rio de Janeiro: Jorge Zahar, 2001.

INPI. Disponível em: <http://www.inpi.gov.br/menu-esquerdo/contrato/tipos-decontrato/fornecimento-de-tecnologia-ft $>$. Acesso em: 14 de jul. de 2010.

KEMMELMEIER, C. S. SAKAMOTO, P. Y. Transferência de tecnologia e as organizações multilaterais. Em: BARRAL, Welber. PIMENTEL, Luiz Otávio (Orgs.). Propriedade intelectual e desenvolvimento. Florianópolis: Fundação Boiteux, p. 129-148, 2006.

MELLO, C. D. de A. Direito internacional econômico. Rio de Janeiro: Renovar, 1993.

PRADO, M. C. de A. Contrato internacional de transferência de tecnologia: patente e know how. Porto Alegre: Livraria do Advogado, 1997.

ROCHA, T. G. P. Proteção da propriedade intelectual pelo TRIPS e transferência de tecnologia. Em: BARRAL, Welber. PIMENTEL, Luiz Otávio (Orgs.). Propriedade intelectual e desenvolvimento. Florianópolis: Fundação Boiteux, p. 149-173, 2006.

SANTOS, Antonio Marques dos. Transferência internacional de tecnologia: algins problemas gerais. Lisboa: Centro de Estudos Fiscais, 1984.

SEN, A. Desenvolvimento como liberdade. Tradução de Laura Teixeira Motta. São Paulo: Companhia das Letras, 2010.

UNIÃO EUROPEIA. Jornal Oficial da União Européia, L123, de 27 de abril de 2004.

ZABALO VIDAURRAZAGA. Concepto y función de la tecnologia, em la obra del Instituto de Estudios Bancarios y Bursatiles. Seminario sobre adquisición de tecnologia extrangera. Bilbao, 1975.

WACHOWICZ, M. Desenvolvimento econômico e tecnologia da informação. Em: BARRAL, Welber. PIMENTEL, Luiz Otávio (Orgs.). Propriedade intelectual e desenvolvimento. Florianópolis: Fundação Boiteux, p. 71/102, 2006.

Submissão: 16/04/2017

Aceito para Publicação: 11/12/2017 
